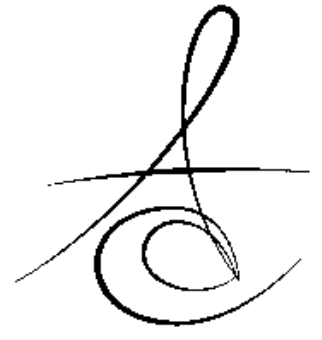

Arş. Gör. Dt. Verda TÜREL*

\title{
BİR ADEZIV SİSTEMİN ÇÜRÜK TESPİT BOYASI, KAN VE TÜKÜRÜKK İLE KONTAMİNE DENTİNE BAĞLANMA DAYANIMININ İNCELENMESİ
}

\section{BOND STRENGHT OF AN ADHESIVE SYSTEM TO DENTIN CONTAMINATED WITH A CARIES DETECTOR DYE, BLOOD AND SALIVA}

Makale Kodu/Article code: 2205

Makale Gönderilme tarihi: 24.03.2015

Kabul Tarihi: 23.05.2015

\section{ÖZET}

Amaç: Bu çalışmanın amacı kan, tükürük ve bir çürük tespit boyası ile kontamine edilen dentin yüzeylerin bir self-etch adezivin mikro-gerilim bağlanma dayanımına etkilerinin değerlendirilmesidir.

Gereç ve Yöntem: Çalışmada son altı ay içinde çekilmiş, on altı adet çürüksüz daimi molar diş kullanıldı. Dişlerin oklüzal kesitlerinden düzgün dentin yüzeyleri elde edildi. Homojen bir dentin yüzeyi elde etmek amacıyla, dentin yüzeyleri 600 gritlik su zımparası ile zımparalandı. Bu yüzeyler kan, tükürük ve çürük tespit boyası ile kontamine edildi. Dişler dört gruba ayrıldı. (I: Kontrol, II: Kan, III: Tükürük, IV: Çürük tespit boyası). Deney gruplarının dentin yüzeylerine kan, tükürük ve çürük tespit boyası uygulandı, sonra durulandı ve kurutuldu. Dişlere selfetch adeziv sistem (Clearfil SE Bond) uygulamasının ardından dişler kompozit rezinle $2 \mathrm{~mm}$ kalınlığında restore edildi. Örnekler 24 saat boyunca $37{ }^{\circ} \mathrm{C}$ distile suda bekletildi. Her bir dişten düşük hızda çalışan elmas separe yardımı ile $1.00 \pm 0.003$ mm kalınlığında beş adet mikro gerilim örneği elde edildi. Örnekler mikro gerilim test cihazına her iki uçlarından siyanoakrilat adezivle yapıştırıldı ve $1 \mathrm{~mm} / \mathrm{dk}$ yükleme hızı altında koparıldı. Verilerin istatistiği tek yönlü varyans analizi ile yapıldı.

Bulgular: Grupların bağlanma değerleri (ortalama \pm SS (MPa)); I: 21.31 \pm 2.15 , II: $5.58 \pm 1.14$, III: 8.33 \pm 1.12 , IV: $17.94 \pm 1.37$ şeklinde bulunmuştur.

Sonuçlar: Dentin yüzeylerinin tükürük ve kan ile kontamine edilmesi self-etch adeziv sistemlerin bağlanma dayanımını olumsuz yönde etkilemektedir. En yüksek bağlanma dayanımı kontrol grubunda görülürken en düşük bağlanma dayanımı kan kontaminasyonu olan grupta gözlenmiştir.

Anahtar kelimeler: Adeziv, Kontaminasyon, Çürük Tespit Boyası, Kan, Tükürük

\section{ABSTRACT}

Aim: The aim of this study was to evaluate the microtensile bond strenght ( $\mu$ TBS) of a self-etch adhesive system to dentin surface contaminated with blood, saliva and caries detector dye.

Material and Method: Sixteen extracted human carious-free permanent molar teeth were used to obtain flat occlusal dentin surfaces. The dentin surfaces were grinded with 600 grid sandpaper underwater irrigation. Teeth were divided into four groups (I: Control, II: Blood, III: Saliva and IV: Caries Detector) Blood, saliva and caries detector dye were applicated on the dentin surfaces, then were rinsed and dried. Teeth were restored with self-etch adhesive system (Clearfil SE Bond) $2 \mathrm{~mm}$ thick composite resin. Then specimens were stored $37^{\circ} \mathrm{C}$ distilled water during 24 hours. Five microtensile specimens from each tooth measuring $1.00 \pm 0.003 \mathrm{~mm}$ were prepared with a slow speed diamond saw sectioning machine with a diamond-rim blade. $(n=20)$. These specimens were attached to opposing arms of the microtensile testing device with cyanoacrylate adhesive and fractured under tension at a crosshead speed of 1 $\mathrm{mm} / \mathrm{min}$. Statistical analysis was made with one-way analysis of variance (ANOVA). $(a=0.05)$

Results: $\mu$ TBS values of groups were (mean \pm SD in MPa); I: $21.21 \pm 2.15$, II: 5.58 \pm 1.14 , III:

$8.33 \pm 1.12$, IV: $17.94 \pm 1.37$. There was significant differences between $\mu$ TBS of groups. $(p<0.05)$

Conclusions: Contamination of dentin with saliva and blood were negatively affected $\mu$ TBS of self-etch adhesive systems. The higher $\mu$ TBS values was observed at control group and the blood contamination group showed lower bond strenght than other groups.

Keywords: Adhesive, Contamination, Caries Detector Dye, Blood, Saliva

${ }^{*}$ Atatürk Üniversitesi, Diş Hekimliği Fakültesi, Restoratif Tedavi Ad 


\section{GİRİŞ}

Restoratif diş hekimliğinin amaçlarından biri, adeziv sistemlerle diş dokuları arasında mükemmel bir bağlanma sağlanmasıdır. Bununla beraber, bu adeziv materyallerin dentine adezyonu yüksek hassasiyet gerektirir ve dentin yüzeyinin kontaminasyonu bağlanmayı olumsuz olarak etkilemektedir. Bu nedenle adeziv rezin restorasyonun başarısı temiz ve kontaminasyonsuz dentin yüzeyi gerektirir. ${ }^{1-3}$

Çürük dentin, enfekte olan dış tabaka ve etkilenmiş dentin tabakası olarak da bilinen iki tabakadan oluşur. Bu iki tabaka ultra-mikroskobik, morfolojik, biyokimyasal, bakteriyolojik ve fizyolojik karakteristikler olarak farklılık gösterir. Çürüğün dış tabakası bakteriyel invazyonun ve yıkımın olduğu alandır. Remineralizasyon kabiliyeti yoktur ve kaldırılması gereklidir. Çürükten etkilenmiş dentin, normal dentine göre daha poröz yer yer demineralize alanlara sahiptir. Sınırlı miktarda kollajen yıkımının gerçekleştiği bu tabaka remineralize olabilme özelliğine sahiptir. Koruyucu diş hekimliği restorasyondan önce enfekte olan dış tabakanın kaldırılması, çürükten etkilenmiş iç tabakanın korunması taraftarıdır.

Çürükten etkilenmiş tabakanın diş preparasyonu esnasında kaldırılmasını önlemek için çeşitli yöntemler kullanılmaktadır. En yaygın kullanılan yöntem gözle yapılan renk kontrolü ve el aletleri ile yapılan sertlik kontrolüdür. Fakat bu yöntem subjektif bir değerlendirme sağlamaktadır. Bunun dışında objektif bir değerlendirme sağlayan $\% 0,5^{\prime}$ lik bazik fuksin veya propilen glikol esaslı çürük tespit boyalarının kullanılması tavsiye edilmektedir. Çürük tespit boyalarının bağlanma dayanımı üzerindeki etkisi hakkında endişeler vardır. Bu boyalar bazen kaviteden uzaklaştırılamayarak dentin yüzeyinde artık materyal olarak kalabil- mektedir., ${ }^{4,5}$

Bu çalışmada hipotezimiz, restorasyon öncesinde kavitenin kan, tükürük ve çürük tespit boyası ile kontaminasyonunun bağlanma dayanımını azaltacağı ve bunun sonucunda düşük bağlanma ile sonuçlanan başarısız restorasyonların elde edileceğidir. $\mathrm{Bu}$ çalışmada yapay tükürük, donörden alınan kan ve çürük tespit boyası ile kontaminasyonun, self-etch bir adezivin dentin bağlanma dayanımına etkisinin değerlendirilmesi amaçlanmıştır.

\section{GEREÇ VE YÖNTEM}

Bu çalışmada 16 adet çekilmiş büyük azı diş kullanıldı. Dişler dentin seviyesinden Isomet (Buehler, Evanston, IL, USA) düşük hızlı kesme cihazı yardımıyla su soğutması altında kesilerek dentin yüzeyleri açığa çıkarıldı. Homojen bir dentin yüzeyi elde edilmesi için, açığa çıkan dentin yüzeyleri 600 gritlik su zımparası ile bir dakika boyunca su altında zımparalandı. Ardından dişler belirtilen şekilde dört gruba ayrıldı;

- Grup I:Kontrol grubu (kontamine edilmeyen grup).

- Grıp II: Dentin yüzeyleri yapay tükürük (Biotene, Oral Balance) ile kontamine edildi.

- Grup III: Dentin yüzeyleri dönörden alınan kan ile kontamine edildi.

- Grup IV: Dentin yüzeyleri çürük tespit boyası (Caries Detector; Kuraray Noritake Dental Inc.,Okayama, Japonya) ile kontamine edildi.

Dentin yüzeyleri kontamine edilerek $10 \mathrm{sn}$ beklendikten sonra hava su spreyi yardımı ile yüzeyleri yıkandı, durulandı ve kurulandı. Dişlerin elde edilen dentin yüzeylerine self-etch adeziv sistem (Clearfill SE Bond, Kuraray, Japonya) üretici firmanın talimatlarına göre uygulanarak 15 sn hava ile kurutuldu. Adeziv uygulanan örnekler Elipar Freelight 2 LCU (3M ESPE Dental Products, St. Paul, Amerika) ışık cihazı ile polimerize edildi. Örneklerin etrafına politetrafluoroe- tilen bant sarılarak Valux Plus (3M ESPE Dental Products, St. Paul, Amerika) kompozit rezin $2 \mathrm{~mm}$ kalınlığında ve üretici firma talimatları doğrultusunda yerleştirildi ve polimerize edildi. Restorasyonu tamamlanan örnekler $37^{\circ} \mathrm{C}$ de distile su içinde 24 saat bekletildi.

Kompozit ile restore edilen diş örneklerinin kökleri, kimyasal olarak sertleşen " L" şeklindeki akrilik bloklara gömüldü. Akrilik bloklar bir uçlarından su soğutmalı kesme cihazına yerleştirildi ve restore edilmiş dişler bağlanma ara yüzeylerine dik olacak şekilde kesilerek $1 \mathrm{~mm}$ kalınlığında dilimler elde edildi. Ardından akrilik bloklar diğer uçlarından kesme cihazına sabitlenerek dişler tekrar dilimlendi ve $1 \pm 0,2 \mathrm{~mm}^{2}$ kesit alanına sahip çubuk şekilli örnekler elde edildi. Her bir dişten temin edilen örneklerden $5^{\prime}$ er tanesi alındı. Daha sonra örnekler mikro-gerilim cihazının (Micro Tensile Tester, BISCO, Inc., Schaumburg, IL, Amerika) test bloğuna siyanoakrilat yapıştırıcı (Zapit, Dental Ventures of America, Inc., Corona, CA, Amerika) ile iki ucundan yapıştırıldı. Örnekte kopma olana kadar $1 \mathrm{~mm} / \mathrm{dk}$ hı ile tensil kuvveti uygulandı. Newton (N) cinsinden elde edilen kırılma değerleri;

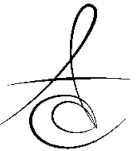


$\mathrm{MPa}=$ Kuvvet(Newton) /Alan(mm2) formülüyle megapaskal (MPa)'a çevrilerek kaydedildi. Verilerin istatistiksel analizi Tek Yönlü ANOVA testi kullanılarak yapıldı $(a=0.05)$

\section{BULGULAR}

Yapılan çalışma neticesinde elde edilen bağlanma değerleri Tablo 1'de gösterilmiştir. Bu sonuçlara göre kontrol grubu ile çürük tespit boyası uygulanan grup II arasında istatistiksel olarak fark bulunmazken ( $p>0.05)$, bu gruplar ile grup II ve grup III arasında istatistiksel olarak önemli farklılıklar bulunmuştur $(p<0.05)$. En yüksek bağlanma değeri kontrol grubunda (21.31 Mpa), en düşük bağlanma değeri ise kan kontaminasyonu olan grup IV'te (5.58 Mpa) gözlenmiştir.

Tablo 1:Örnek sayısı, grupların ortalama bağlanma kuvvetleri ve standart sapmaları

\begin{tabular}{|l|c|c|c|}
\hline Grup & $\mathbf{n}$ & $\begin{array}{c}\text { Ortalama } \\
(\mathbf{M p a})\end{array}$ & $\begin{array}{c}\text { Standard } \\
\text { Sapma }\end{array}$ \\
\hline Grup I & 20 & $21.31^{\mathbf{a}}$ & 2,15 \\
\hline Grup II & 20 & $19.94^{\mathbf{a}}$ & 1,37 \\
\hline Grup III & 20 & $8.33^{\mathbf{b}}$ & 1,12 \\
\hline Grup IV & 20 & $5.58^{\mathbf{c}}$ & 1,14 \\
\hline
\end{tabular}

Farklı üst simgeler istatiksel olarak farklı ortalamaları belirtmektedir $(p<0.05)$

\section{TARTIŞMA}

Bu çalışmada tükürük, kan ve çürük tespit boyası ile kontaminasyonun self-etch bir adeziv olan Clearfil SE Bond'un dentin bağlanma dayanımı üzerine etkileri incelenmiştir. Çalışma sonucunda dentinin tükürük ve kanla kontaminasyonunun, self-etch adezivlerin bağlanma dayanımı üzerine istatistiksel olarak anlamlı derecede olumsuz etkiye sahip olduğu görülmüştür. $(p<0.05)$

Çoğunlukla adezivlerin bağlanma dayanımlarını belirlemek amacıyla germe, makaslama, mikro-germe ve mikro-makaslama testleri kullanılmaktadır. ${ }^{6} \mathrm{Bu}$ çalışmada yaygın ve kolay bir metot olması nedeniyle mikro-gerilme bağlanma dayanım testi kullanılmıştır.
Itoh ve ark. ${ }^{7}$ larının metal braketlerin kan ve tükürük ile kontamine olmuş mineye bağlanmasını inceledikleri araştırmada kan ve tükürük örnekleri arasında farklı sonuçlar çıkmasını kan ve tükürüğün içerdikleri organik ve inorganik komponentlerin miktarı ve tipindeki farklıı̆̆a bağlamışlardır.

Çürük tespit boyasının adezivlerin dentine olan bağlanma dayanımlarına etkisi ile ilgili yapılan çalışmalar mevcuttur. Kazemi ve ark. ${ }^{8}$ yaptıkları bir çalışmada iki farklı çürük tespit boyasının üç farklı adeziv sistemin sağlam dentine bağlanma dayanımına etkisini araştırmışlar ve çalışmada deney gruplarında sağlam dentin yüzeyleri 10 saniye boyunca çürük tespit boyası ile işlem gördükten sonra su ile yıkanmış ve ardından adeziv sistemler uygulanarak restorasyonlar yapmışlarıdır. Elde edilen sonuçlara göre, kullanılan çürük tespit boyasının bu adeziv sistemlerin sağlam dentine olan bağlanma dayanımlarını etkilemediği sonucuna varılmıştır.

Yokota ve ark. ${ }^{9}$ çürük tespit boyası Caries Detector ve Caries Detector'ün içeriğinde de bulunan Acid Red 52 ve Propilen glikol'ün 4 farklı adeziv sistemin bağlanma dayanımına olan etkisini araştırmışlardır. Çalışmada her bir adeziv için kontrol grubu, Acid Red 52'nin uygulanıp hava ile kurutulduğu grup, Propilen glikol'ün uygulanıp hava ile kurutulduğu grup, Caries Detector'ün yüzeye uygulanıp yıkanıp hava ile kurutulduğu ve Caries Detector'ün yüzeye uygulanıp sadece hava ile kurutulduğu gruplar olmak üzere toplam 20 grup oluşturulmuştur. Çalışmadan elde edilen bulgulara göre Propilen glikol tüm adezivlerin bağlanma dayanımını anlamlı derecede düşürmüştür. Acid Red 52 hiçbir adezivin bağlanma dayanımını etkilememiştir. Caries Detector'ün uygulamadan sonra yıkandığı gruplarda bağlanma dayanımı değişmezken, sadece hava ile kurutulan gruplarda iki adezivde bağlanma dayanımı düşmüştür. Araştırmacılar Caries Detector içeriğinde bulunan propilen glikol'ün adezivlerin bağlanma dayanımını olumsuz etkilediğini ve bu nedenle Caries Detector uygulandıktan sonra diş yüzeyinin mutlaka su ile yıkanması gerektiğini bildirmişlerdir.

Koppolu ve ark. ${ }^{10}$ adhesiv uygulamadan önce ve adhesiv uyguladıktan sonra tükürük ve kanla kontami- ne ettikleri mine ve dentin yüzeylerinin adeziv bağlan- ma değerlerini araştırmışlardır. Kontamine edildikten sonra yıkanıp kurutulan ve daha sonra adeziv uygula- nan mine ve dentin örneklerinde, adeziv uygulandıktan sonra kontamine edilen mine ve 
dentin örneklerine göre bağlanma değerleri daha yüksek bulunmuş ve tükürük ile kontamine edilen örneklerde bağlanma değeri kanla kontamine edilen örneklere göre daha yüksek bulunmuştur.

Çalışmamızda kullandığımız Caries Detector uygulanan örneklerin yüzeyi su ile yıkanıp kurutulmuştur ve bağlanmada anlamlı bir düşme olmamıştır. Çalışmamızdan farklı bir şekilde Demarco ve ark. ${ }^{11}$ çürük tespit boyası uyguladıkları sağlam dentini kompozit ve kompomer ile restore etmişler ve mikro-gerilme bağlanma dayanımında azalma tespit etmişlerdir. Araştırmacı bu sonucu yıkama ve asit uygulama sonucu bile uzaklaşmayan artık boyaya bağlamıştır.

Ünlü ve ark. ${ }^{12}$ yaptıkları bir çalışmada iki farklı total etch ve üç farklı self-etch adeziv sistem uygulanmak üzere rastgele beş grup oluşturmuşlar ve her bir grubu biri kontrol olan üç farklı kanama durdurucu ajan uygulanmak üzere dört alt gruba bölmüşlerdir. Self-etch bondinglerin kontamine dentine bağlanma dayanımlarını kontrol grubundan oldukça daha düşük bulmuşlardır. Self-etch adeziv sistemlerin dentine bağlanma mekanizmaları smear tabakasının değiştirilmesi ve açığa çıkan kollajen fibrillere bonding ulaşması ile oluşan hibrit tabaka aracılığıyla olur. ${ }^{13-15}$ Fakat Ünlü ve ark. ${ }^{12}$ kullandıkları self-etch sistemlerin primerinin zayıf ve orta asitliğe sahip olduğu ve ilave yıkama işlemi içermedikleri gibi sebeplerle istenilen kalınlıkta hibrit tabakası oluşturacak kadar koagüle ajanları uzaklaştıramadıkları için bağlanma dayanımlarının düşmüş olabileceğini iddia etmişlerdir. Bu yüzden selfetch sistemler kontaminasyona karşı oldukça hassastır.

\section{SONUÇLAR}

Çalışmamızın sonuçlarına göre kan ve tükürük ile dentin yüzeylerinin kontamine edilmesi, self-etch adeziv sistemlerin bağlanma dayanımını olumsuz yönde etkilemektedir. Restorasyon yapımı sırasında kavitenin kan ve tükürükten korunması önemli bir faktördür. Çürük teşhisinde önemli bir yer tutan boyayıcı ajanların self-etch adezivin bağlanmasına olumsuz etkisinin olmaması, bu ajanların kullanımı açısından önemli bir avantajdır.

\section{KAYNAKLAR}

1. Ayaz F, Tağtekin D, Yanıkoğlu F, Dentine Bağlanma ve Değerlendirme Metotları. Ata. Üniv. Diş Hek Fak Derg 2011; 4: 49-56.

2. Güller F, Şimşek M, Cebe F, Yıldız E, Yıldııım C. Bir adeziv sistemin kanama durdurucu ajanlarla kontamine edilen dentin yüzeyine bağlanma dayanımı. Cumhuriyet Dent. J.2014;17:42-7.

3. Xie J, Powers JM, McGuckin RS. In vitro bond strength of two adhesives to enamel and dentin under normal and contaminated conditions. Dent Mater 1993;9:295-9.

4. Yalçın M, Cebe F, Cebe MA. Çürük Tespit Boyalarının Çürükten Etkilenmiş Dentinde Bağlanma Dayanımı Üzerine Etkisi. Cumhuriyet Dent J 2014;17:135-42.

5. Singh UP, Tikku A, Chandra A, Loomba K, Boruah LC. Influence of caries detection dye on bond strength of sound and carious affected dentin: An in-vitro study. J Conserv Dent 2011; 14:32-5.

6. Salz $U$, Bock $T$. Testing adhesion of direct restoratives to dental hard tissue - a review. J. Adhes Dent2010; 12:343-71.

7. Itoh, T. Fukushima, Y. Inoue, S. Arita, K. Miyazaki. Effect of water saliva and blood contamination on bonding of metal brackets with a 4-META/MMA/TBB resin to etched enamel. Am J Dent 1999; 12:299-304.

8. Kazemi RB, Meiers JC, Peppers K. Effect of caries disclosing agents on bond strengths of total-etch and self-etching primer dentin bonding systems to resin composite. Oper Dent 2002; 27:238-42.

9. Yokota H, Kubo S, Ohsawa M, Hayashi Y. Effect of a caries detecting solution on the tensile bond strength of four dentin adhesive systems. Dent Mater J 2006; 25:66-74.

10. Koppolu M, Gogala D, Mathew VB, Thangala V, Deepthi M, Sasidhar N. Effect of saliva and blood contamination on the bond strength of self-etching adhesive system- An in vitro study. J Conserv Dent. 2012 Jul; 15:270-3.

11. Demarco FF, Matos AB, Matson E, Powers JM Dyes for caries detection influence sound dentin bond Strenght.1998; Oper Dent 23:294-8. 
12. Ünlü N, Çetin A, Cebe M, Karabekir S. Comparison of Micro Tensile Bond Strength of Different Adhesive Systems to Dentin Contaminated with Homeostatic Agents. Hacettepe Üniv Diş Hek Fak Derg 2010; 34:3-4.

13. Chung CWM, Yiu CKY, King NM, Hiraishi N, Tay FR. Effect of saliva contamination on bond strength of resin luting cements to dentin. J Dent 2009; 37:923-31.

14. Xie J, Powers JM, Mc Guckin RS. In vitro bond strength of two adhesives to enamel and dentin under normal and contaminated conditions. Dent Mater 1993; 9:295-9.

15. Unemori M, Matsuya Y, Akashi A, Goto Y, Akamine A. Self-etching adhesives and postoperative sensitivity. Am J Dent 2004; 17:191-5.

\author{
Yazışma Adresi: \\ Dt. Verda TÜREL \\ Atatürk Üniversitesi , Diş hekimliği Fakültesi \\ Restoratif Tedavi A.D. 25240/ Erzurum \\ Tel:0442 2313882 \\ E-mail: r_verda@hotmail.com
}

